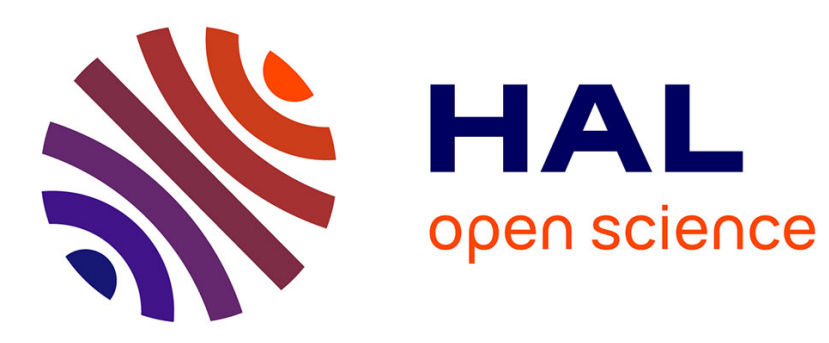

\title{
Affect in Complex Decision-Making Systems: From Psychology to Computer Science Perspectives
}

\author{
Amine Chohra, Aziza Chohra, Kurosh Madani
}

\section{To cite this version:}

Amine Chohra, Aziza Chohra, Kurosh Madani. Affect in Complex Decision-Making Systems: From Psychology to Computer Science Perspectives. 10th IFIP International Conference on Artificial Intelligence Applications and Innovations (AIAI), Sep 2014, Rhodes, Greece. pp.174-183, 10.1007/978-3662-44722-2_19. hal-01391044

\section{HAL Id: hal-01391044 \\ https://hal.inria.fr/hal-01391044}

Submitted on 2 Nov 2016

HAL is a multi-disciplinary open access archive for the deposit and dissemination of scientific research documents, whether they are published or not. The documents may come from teaching and research institutions in France or abroad, or from public or private research centers.
L'archive ouverte pluridisciplinaire HAL, est destinée au dépôt et à la diffusion de documents scientifiques de niveau recherche, publiés ou non, émanant des établissements d'enseignement et de recherche français ou étrangers, des laboratoires publics ou privés. 


\title{
Affect in Complex Decision-Making Systems: from Psychology to Computer Science Perspectives
}

\author{
Amine Chohra, Aziza Chohra, and Kurosh Madani \\ Images, Signals, and Intelligent System Laboratory (LISSI / EA 3956), Paris-East University \\ (UPEC), Senart Institute of Technology, Avenue Pierre Point, Lieusaint 77127, France \\ \{chohra, madani\}@u-pec.fr, http://www.lissi.fr, \\ http://chohra.webs.com
}

\begin{abstract}
The increasing progresses in both psychology and computer science allow continually to deal with more and more complex systems and closer to real-world applications in order to solve particularly the decision-making process with uncertain and incomplete information. The aim of this research work is to highlight the irrationality (affect) and to understand some different ways in which the irrationality enter into the decision-making from psychology and computer science perspectives. The goal is also to present some of such integrations of affect in decision-making which emerged in computer science particularly in negotiation and robotics. Thus, the role of the affect in decision-making is developed and discussed. Afterwards, an overview is given on the influence of the affect on an individual level emphasizing the idea that irrationality also has strong social components which can influence the interactions on a group (collective) level. Then, the Emotional Intelligence (EI) is discussed as a first step towards an attempt to answer to how to regulate/control the irrationality part for óositiveôdecision-making, and consequently its effects on the though and action. Finally, some developments of computational models are presented. Open questions and challenges are discussed in conclusion, particularly the importance of the personality and its links to the affect.
\end{abstract}

Keywords. Complex systems, decision-making, uncertain and incomplete information, affect (emotions and moods), personality, negotiation and robotics

\section{Introduction}

Affect (or feelings) is the overarching category, which incorporates moods and emotions [1]. Emotions are specific (e.g., anger, happiness, fear, é ) and brief subjective feelings, which usually have an identifiable cause (e.g., Iôm angry with é ) [1]. Moods, on the other hand, are usually more diffuse (e.g., good or bad mood) and weaker feeling states, and tend to lack source identification (e.g., Iôm in a bad mood).

Throughout recorded human intellectual history, there has been active debate about the nature of the role of emotions or p̃passionsò in human behavior [2], with the dominant view being that passions are a negative force in human behavior [3]. By 
contrast, some of the latest research has been characterized by a new appreciation of the positive functions served by emotions [4]. An appreciation for the positive functions is not entirely new in behavioral science. Darwin, in 1872, was one of the first to hypothesize the adaptive mechanisms through which emotion might guide human behavior [5].

The increasing progress in computer science and information technology allowed to deal with more complex systems and closer to real-world applications in order to solve particularly the decision-making problems. Traditionally, the decision-making was viewed as a rational process where reason calculates the best way to achieve the goal. Investigations from different areas of cognitive science have shown that human decisions and actions are much more influenced by intuition and emotional responses than it was previously thought [6], [7], [8], [9].

Emotions are one of the important subconscious mechanisms that influence human behaviors, attentions, and decision making. The emotion process helps to determine how humans perceive their internal status and needs in order to form consciousness of an individual. Emotions have been studied from multidisciplinary perspectives and covered a wide range of empirical and psychological topics, such as understanding the emotional processes, creating cognitive and computational models of emotions, and applications in computational intelligence.

This paper deals with a review on the role of the affect (emotions and moods) on decision-making from psychology perspective, and the awareness to such role from computer science perspective. The goal is also to emphasize some central topics emerged from such integrations of the irrationality part (emotions and moods, personality) in the decision-making of complex systems with uncertain and incomplete information, particularly in computer science research fields such as in negotiation and robotics.

Thus, the role of the affect in decision-making is developed and discussed in Sect. 2. Afterwards, an overview is given on the influence of the affect on an individual level, in Sect. 3, emphasizing the idea that irrationality also has strong social components which can influence the interactions on a group (collective) level. Then, the Emotional Intelligence (EI) is discussed in Sect. 4, as a first step towards an attempt to answer to how to regulate/control the irrationality part for óositiveôdecisionmaking, and consequently its effects on the though and action. Finally, some developments of computational models are presented in Sect. 5. Open questions and challenges are discussed in Sect. 6, particularly the importance of the personality and its links to the affect.

\section{The Role of the Affect in Decision-Making}

Until middle of 1990s, the affect (emotions and moods) attracted little attention from researchers on decision-making. In fact, the decision-making was viewed, in general, as a cognitive process: a matter of estimating which of various alternative actions would yield the most positive consequences [2]. The research community 
which emerged in the late 1960s under the heading of behavioral decision theory largely adhered to this cognitive perspective.

The main thrust of behavioral decision theory [2] has been to identify:

- cognitive errors that people make when they judge the likelihood of future consequences,

- simplifying heuristics that people use to cope with the complexity of decisionmaking.

The great interest and large investigations in decision-making research associated with the emergence of behavioral decision theory, then, largely ignored the role played by the irrationality part, related to affect in general, in decision-making [2].

However, with the research developments particularly psychology-related fields from 1990s, a great interest have been oriented towards the role of the irrationality part related to emotions in decision-making. Research has shown that:

- even incidental affect (emotion and mood), affect that is unrelated to the decision at hand, can have a significant impact on judgment and choice [10],

- emotional deficits, whether innate [4] or experimentally induced, can degrade the quality of decision-making,

- incorporating affect (emotion and mood) in models of decision-making can greatly increase their explanatory power.

From the perspective of neuroscience and psychology, Antonio Damasio [4] states that an important part of the decision-making process consists of the comparison of potential alternatives with emotions and feelings from similar past situations. Furthermore, the process also involves the estimation of results brought about by these past events and potential rewards or punishments that might have been gained during such events. This procedure enables us to simulate potential future outcomes based on our past experiences and then opt for a move that will lead to the best possible solution.

Thus, contemporary decision-making research is characterized by an intense focus on the irrationality part, related to affect in general [2].

When studying the effects of affect (emotion) on judgment, decision, and behavior, two types of affective (emotional) phenomena should be distinguished: incidental emotional states and integral emotional responses [11], [12], [6].

Loewenstein and Lerner [2] classify according to their place along the time course of a decision process, beginning with a deliberation phase leading to a choice, then implementing the choice, and, eventually, experiencing the outcomes. They distinguish between anticipated emotions and immediate emotions, with immediate emotions further classiýed into incidental and anticipatory emotions. Anticipated emotions are beliefs about oneôs future emotional states that might ensue when the outcomes are obtained. Immediate emotions, in contrast, are actually experienced when making a decision, thereby exerting an effect on the mental processes involved in making a choice; for similar distinctions see [13]. Immediate emotions come in two variants, either as incidental emotions caused by factors which are not related to the decision problem at hand, and as anticipatory or integral emotions, which are caused by the decision problem itself. 
There is ample evidence that these kinds of emotion frequently do inpuence the judgments and choices people make. Lerner and Keltner [10] demonstrated the effects of incidental fear and anger on risk judgments. The inpuence of immediate anticipatory emotions in intertemporal choice has been examined by Loewenstein 1996, see [2], [14]. The importance of anticipated emotions such as anticipated regret and disappointment in decision making has been demonstrated by Zeelenberg, van Dijk, Manstead, and van der Pligt 2000, see [Pfister2008].

Recently, Peters, Västfjäll, Gärling, and Slovic, in 2006 proposed another classiýcation of the roles that affect plays in decision making, see [14]. Affect is loosely deýned as experienced feelings about a stimulus, either integral or incidental. Four roles are identiýed:

- First, affect plays a role as information, especially via the affect as information mechanism, Schwarz and Clore 1988. These feelings, possibly misattributed to the stimulus, act as good-versus-bad information to guide choices, according to the affect heuristic proposed by Slovic, Finucane, Peters, and MacGregor 2002.

- The second role played by affect is as a spotlight, focusing the decision makerôs attention on certain kinds of new information and making certain kinds of knowledge more accessible for further information processing. This role is reminiscent of moodcongruent memory as studied by Bower 1991.

- Third, affect operates as a motivator, in puencing approach-avoidance tendencies as well as efforts to process information Frijda, 1986 ; Zeelenberg and Pieters 2006.

- Finally, a fourth role of affect is to serve as a common currency in judgments and decisions Cabanac 1992. Just as money does for goods, affect provides a common currency for experiences. Following Cabanac 1992, Peters claims that affective reactions enable people to compare disparate events and complex arguments on a common underlying dimension, see [14].

Another interesting four-fold classiýcation of emotional mechanisms is given in [14] by Pfister which is similar to the Peters approach in some respects, and where the commonalities and differences are discussed.

Thus, several other researchers investigate the role of affect in decision making from different point of views [15], [16], [17], [3], [18], [19], [20], [9], [21].

By another way, until the end of 1990s, works from computer science research fields implying Artificial Intelligence and particularly robotics have been limited and mostly oriented towards synthetic agents, and while some robot systems incorporate emotions, they focus too much on emotional expression, leaving behind perhaps some of the most important functions and aspects of emotional processing, such as their influence in behavior selection, coherence, relevance, and learning.

Thus, a transition has been done in order to deal with more sensing abilities and a larger repertoire of behaviors (than navigation, obstacle avoidance, localization, é ). In fact, such transition emerged from many research efforts which have shifted from behavior-based approaches that deal with insect-level competence, to those that try to build robot systems that exhibit behaviors comparable in complexity to those of humans, as it is the case in friendly robotics and cognobotics [22].

As Brooks 1997 has eloquently argued, the robotic systems must manipulate the world and interact in it in non-trivial ways. This requires a much richer set of abilities 
to obtain sensory information and coordinate motor control, as well as an increased and more complex behavioral repertoire that includes, among other competences, the ability to interact socially. However, robots that exhibit robust and adaptive behavior, and which are responsive to social interactions, must deal with issues such as motivation and emotion which have not been essential in behavior-based robotics, see [22].

Thus, Juan D. Velasquez proposed in [23], [22] an emotion-based approach to robotics that relies on the use of computational frameworks for the emotion-based control: control of autonomous agents that relies on, and arises from, emotional processing. In this work, six different types of affect programs have been identified and created in explicit models: anger, fear, distress/sorrow, joy/happiness, disgust, and surprise [22].

In negotiation, Li developed a strategic emotion in negotiation implying emotion, cognition and culture [24]. A one to one bargaining process, in which a buyer agent and a seller agent negotiate over single issue (price), is developed, where the basic behaviors based on time and personality aspects (conciliatory, neutral, and aggressive) have been suggested [25].

\section{Emotion on Individual and Group (Collective) Levels}

There have been three major contexts within which researchers have studied the effects of affective states on intergroup perception and behavior. Two of the domains have to do with affect that is elicited by the group itself and the social situations within which the group is experienced (termed ñintegralò affect by Bodenhausen, 1993). Research on chronic integral affect has examined the impact of enduring affective reactions to the social group on attitudes and behavior toward the group and its members. Research on episodic integral affect has examined the impact of affective reactions that are situationally created in intergroup settings, which may in principle be quite different from more chronic feelings about the group (as when one has a pleasant interaction with a member of an otherwise disliked group). The final domain involves affective states that arise for reasons having nothing to do with the intergroup context itself, but which are carried over from other events into an intergroup setting (termed ñncidental affectò by Bodenhausen, 1993), see [11], [12].

By another way, Treur developed agent models from social neuroscience concepts and discussed how such neurological concepts can be used to obtain emergence of shared understanding and collective power of groups of agents, both in a cognitive and affective sense [26]. A generic contagion model is then developed emphasizing the idea that irrationality also has strong social components which can influence the interactions on a group (collective) level, see also [27].

Also, Becker Asano and Wachsmuth designed the ñWASABIò affect simulation architecture, which uses a three-dimensional emotion space called PAD (PleasureArousal-Dominance) space [28]. In this study, social robots generate and express their emotions in human-robot interaction. 


\section{$4 \quad$ Emotional Intelligence (EI)}

"All learning has an emotional base." from the greek philosopher Plato. Emotional Intelligence (EI) refers to the ability to perceive, control and evaluate emotions. Some researchers suggest that EI can be learned and strengthened, while others claim it is an inborn characteristic.

Since 1990, Peter Salovey and John D. Mayer [29] have been the leading researchers on EI. In their influential article "Emotional Intelligence, in 1990" they defined EI as, "the subset of social intelligence that involves the ability to monitor one's own and others' feelings and emotions, to discriminate among them and to use this information to guide one's thinking and actions".

Thus, several research works have been developed on EI [30], [31], [32].

\section{Computational Models}

An excellent review is given on the development of computational models of emotions for autonomous agents in [33]. Particularly, the comprehensive survey where five design aspects that influence the development process of computational models are investigated: theoretical foundations, operating cycle, cognition and emotion interaction, architecture design, and role in cognitive agent architectures.

A comprehensive survey of cognitive and computational models of emotions resulted from multidisciplinary studies is given in [34]. It explores how cognitive models serve as the theoretical basis of computational models of emotions. The mechanisms underlying affective behaviors are examined as important elements in the design of these computational models. A comparative analysis of current approaches is elaborated based on recent advances towards a coherent cognitive computational model of emotions, which leads to the machine simulated emotions for cognitive robots and autonomous agent systems in cognitive informatics and cognitive computing.

Because of the multiple facets and components underlying the process of human emotions, it can be approached from a diversity of perspectives. Moreover, due to the nature of this process and its applications, emotions are currently the focus of study in multiple disciplines such as psychology, neuroscience, philosophy, computer science, cognitive sciences, and cognitive informatics [34]. This multidisciplinary inquiry has provided evidence that shows the significance of emotions not only to the rational behavior of individuals, but to achieve more believable and human-like behaviors in intelligent systems. In particular, fields such as psychology and neuroscience have contributed a number of theories and models that explain the diversity of the emotion process. These theories are focused on revealing the mechanisms underlying the process by which humans transform external stimuli into emotional perspectives. Similarly, in fields such as computer science, cognitive informatics, computational intelligence, and artificial intelligence, researchers are interested in the design of formal and computational models of emotions that help improve Artificial Intelligent systems used for cognitive robots, autonomous agents, and human-computer interactions [34]. In this dual approach, computational modeling technologies are used for testing and 
refining psychological, biological, and cognitive models, which are further used to support the design of computational models of emotions. [39].

Thus, several computational models have been developed [35], [36], [37], [38],

\section{Discussion and Conclusion}

In this paper, the role of the affect in decision-making has been developed and discussed. Afterwards, an overview is given on the influence of the affect on an individual level emphasizing the idea that irrationality also has strong social components which can influence the interactions on a group (collective) level. Then, the Emotional Intelligence (EI) has been discussed as a first step towards an attempt to answer to how to regulate/control the irrationality part for q́positiveôdecision-making, and consequently its effects on the though and action. Finally, some developments of computational models have been presented.

Throughout the paper, the goal was also to present some of such integrations of affect in decision-making which emerged in computer science particularly in negotiation and robotics.

In the following, some open questions and challenges are discussed.

First, it is very important to discuss the importance of the personality and its links to the affect. A brief definition would be that personality is made up of the characteristic patterns of thoughts, feelings and behaviors that make a person unique. In addition to this, personality arises from within the individual and remains fairly consistent throughout life. "Personality refers to individuals' characteristic patterns of thought, emotion, and behavior, together with the psychological mechanisms -- hidden or not - behind those patterns. This definition means that among their colleagues in other subfields of psychology, those psychologists who study personality have a unique mandate: to explain whole persons." Funder 1997.

"Although no single definition is acceptable to all personality theorists, we can say that personality is a pattern of relatively permanent traits and unique characteristics that give both consistency and individuality to a person's behavior." Feist 2009.

"Having closed in on a sense of what personality is, it may be helpful to compare the concept to others with related meanings. Two concepts that quickly come to mind are 'temperament' and 'character.' In everyday language these terms are sometimes used more or less interchangeably with 'personality,' and historically they have often been used in contexts where, in more recent times, 'personality' would be employed. Within psychology, however, they have somewhat distinct meanings. Temperament usually refers to those aspects of psychological individuality that are present at birth or at least very early on in child development, are related to emotional expression, and are presumed to have a biological basis... Character, on the other hand, usually refers to those personal attributes that are relevant to moral conduct, self-mastery, willpower, and integrity." Haslam 2007.

A very well known model of the personality is the five-factor model in personality developed in [40]. An example of negotiation based on such five-factor model has been developed in [41]. 
Thus, several research works have been developed using the affect and personality [42], [43].

Another open question is related to the philosophers Solomon and Stone 2002, see [8], recently reviewed the emotion literature and concluded that: The analysis of emotions in terms of ñvalence,ò while it recognizes something essential about emotions... is an idea that we should abandon and leave behind. It serves no purpose but confusion and perpetrates the worst old stereotypes about emotion, that these are simple phenomena unworthy of serious research and analysis. The idea is that if we really want to understand emotion and emotionôs impact we have to go beyond mere valence [8].

Another interesting alternative for future consists to investigate the research work initiated in [44]. The interest in this issue is that Authors not used a predefined human emotional model but tried to create an agent (robot) specific emotional architecture under the assumption that emotions are unique to an agentôs possible interactions with its world.

\section{References}

1. E. B. Andrade and D. Ariely: The Enduring Impact of Transient Emotions on DecisionMaking; Organizational Behavior and Human Decision Processes, 109, Elsevier, pp. 01-08 (2009)

2. G. Loewenstein and J. S. Lerner (2003); The Role of Affect in Decision-Making; In R. J. Davidson, K. R. Scherer and H. H. Goldsmith, Handbook of Affective Sciences, Oxford University Press (pp. 619-642)

3. J. Elster: Alchemies of the Mind: Rationality and the Emotions. Cambridge, England: Cambridge University Press (1999)

4. A. R. Damasio, ñDescartesô Error: Emotion, reason, and the human brainò, New York: Putnam, 1994.

5. C. Darwin, ñThe Expression of the Emotions in Man and Animalsò, Original Work Published in 1872 and Produced by Charles Keller and David Widger, $3^{\text {rd }}$ ed. New York: Oxford University Press, 1998.

6. Pham, M.T.: Emotion and rationality: a critical review and interpretation of empirical evidence. Review of General Psychology 11(2), American Psychological Association, 155178 (2007)

7. Seo, M.-G., Barrett, L.F.: Being emotional during decision making ï good or bad ? an empirical investigation. Academy of Management Journal 50(4), 923-940 (2007)

8. Zeelenberg, M., Nelissen, R.M.A., Breugelmans, S.M., Pieters, R.: On emotion specificity in decision making: why feeling is for doing. Judgment and Decision Making 3(1), 18-27 (January 2008)

9. O. Markic, O.: Rationality and emotions in decision-making. Interdisciplinary Description of Complex Systems 7 (2): 54-64 (2009)

10. Lerner, J. S., Keltner, D.: Beyond valence: Toward a model of emotion-speciýc inpuences on judgement and choice. Cognition and Emotion, 14(4), 473-493 (2000b)

11. Bodenhausen, G.V., Mussweiler, T., Gabriel, S., Moreno, K.N.: Affective influences on stereotyping and intergroup relations. Chapter in J.P. Forgas (Ed.), Handbook of Affect and Social Cognition, Lawrence Erlbaum Associates Publishers, Mahwah, New Jersey (2001) 
12. J.P. Forgas (Ed.): Handbook of Affect and Social Cognition. Lawrence Erlbaum Associates Publishers, Mahwah, New Jersey (2001)

13. Kahneman, D.: Experienced utility and objective happiness: A moment-based approach. In D. Kahneman\&A.Tversky(Eds.), Choices, values, and frames (pp. 673-692). Cambridge: Cambridge University Press.

14. Pfister, H.-R., Böhm, G.: The multiplicity of emotions: a framework of emotional functions in decision making. Judgment and Decision Making 3(1), 5-17 (January 2008)

15. Kahneman, D., Tversky, A.: Prospect theory: an analysis of decision under risk. Econometrica, 47(2): 263-292 (1979)

16. R. L. Keeney, ñDecision Analysis: An Overviewò, Operations Research, Vol. 30, No. 5, pp. 803-838, September-October 1982 [Becker-Asano2008] C. Becker-Asano, C., Wachsmuth, I.: Affect simulation with primary and secondary emotions. in Intelligent Virtual Agents, H. Prendinger, J. Lester, and M. Ishizuka, Eds., Springer, LNCS 5208, $15 \mathrm{Ï} 28$ (2008)

17. J. S. Hammond, R. L. Keeney, and H. Raiffa, ñThe Hidden Traps in Decision Makingò, Harvard Business Review, pp. 01-11, September-October 1998.

18. Raiffa, H.: Decision Analysis: a personal account of how it got started and evolved. Operations Research 50(1), 179-185 (January-February 2002).

19. Naqvi, N., Shiv, B., Bechara, A.: The role of emotion in decision-making: a cognitive neuroscience perspective. Association for Psychological Science, 15(5), 260-264 (2006)

20. Niedenthal, P.M.: Embodying emotion. Science, 316(5827):1002-1005 (2007)

21. Ahn, H.-I: Modeling and Analysis of Affective Inpuences on Human Experience, Prediction, Decision Making, and Behavior. PhD Thesis, Massachusetts Institute of Technology, (2010)

22. Velasquez, J. D.: An emotion-based approach to robotics. Proc. of the IEEE/RSJ Int. Conf. on Intelligent Robots and Systems, 1: 235-240 (1999)

23. Velasquez, J. D.: When robots weep: emotional memories and decision-making. Proc. of the American Association for Artificial Intelligence (1998)

24. Li, S., Roloff, M.E.: Strategic emotion in negotiation: cognition, emotion, and culture. G. Riva, M. T. Anguera, B. K. Wiederhold, and F. Mantovani (Eds.) From Communication to Presence: Cognition, Emotions and Culture towards the Ultimate Communicative Experience, IOS Press Amsterdam, 169-188 (2006)

25. Chohra, A., Bahrammirzaee, A., Kanzari, D., Madani, K.: Personality aspects and fuzzy logic for bilateral negotiation behaviors with incomplete information. Chapter 12 in the Book ớBidding: Types, Strategies and the Impact of Irrationalityô̂ Ming K. Lim Editor, Nova Science Publishers, New York: 251-276 (2013)

26. Treur, J.: From mirroring to the emergence of shared understanding and collective power. Keynotes in Computational Collective Intelligence Technologies and Applications, P. Jedrzejowicz, N. T. Nguyen, K. Hoang (Eds.), Springer, LNAI 6922: 01-16 (2011)

27. Duell, R., Treur, J.: A Computational Analysis of Joint Decision Making Processes. Social Informatics, Springer, 01-14 (2012)

28. C. Becker-Asano, C., Wachsmuth, I.: Affect simulation with primary and secondary emotions. in Intelligent Virtual Agents, H. Prendinger, J. Lester, and M. Ishizuka, Eds., Springer, LNCS 5208, 15 Ï 28 (2008)

29. Salovey, P., Mayer, J.: Emotional intelligence. Imagination, cognition, and personality, 9(3), 185-211 (1990)

30. Mayer, J.D., Salovey, P.: The intelligence of emotional intelligence. Intelligence 17, 433442 (1993) 
31. Elfenbein, H.A., Marsh, A.A., Ambady, N.: Emotional intelligence and the recognition of emotion from facial expressions. The Wisdom of Feelings: Processes Underlying Emotional Intelligence, Lisa Feldman Barret and Peter Salovey (Editors), 01-19 (2003)

32. Barsade, S.G., Gibson, D.E.: Why does affect matter in organizations ?. Academy of Management of Perspectives, 36-59 (February 2007)

33. Rodriguez, L.-F., Ramos, F.: Development of computational models of emotions for autonomous agents: A review. Cognitive Computation, DOI 10.1007/s 12559-013-9244-x, Springer, (January 2014)

34. Wang, Y., Rodriguez, L.-F., Ramos, F.: Cognitive computational models of emotions and affective behaviors. Int. J. of Software Science and Computational Intelligence, 4(2), 4163 (April 2012)

35. Gratch, J., Marsella, S.: Evaluating a computational model of emotion. Autonomous Agents and Multi-Agent Systems, Springer, (2005)

36. Ochsner, K.N., Gross, J.J.: The cognitive control of emotion. Trends in Cognitive Sciences, 9(5), 242-249 (May 2005)

37. Marsella, S., Gratch, J., Petta, P.: Computational models of emotion. Scherer, K.R., Banziger, T., Roesch, E. (Eds.), A Blueprint for an affectively Competent Agent: CrossFertilization Between Emotion, Psychology, Affective Neuroscience, and Affective Computing, Oxford University Press (2010)

38. Lin, J., Spraragen, M., Blythe, J., Zyda, M.: EmoCog: computational integration of emotion and cognitive architecture. Association for the Advancement of Artificial Intelligence, (2011)

39. Lin, J., Spraragen, M., Zyda, M.: Computational models of emotion and cognition. Advances in Cognitive Systems 2, 59-76 (2012)

40. McAdams, D.P.: The five-factor model in personality: a critical appraisal. Journal of Personality 60(2), 329-361 (June 1992)

41. A. Chohra, A., Bahrammirzaee, A., Madani, K.: Time and personality based behaviors to control the negotiation process with incomplete information. Transactions on Computational Collective Intelligence XII, Springer, LNCS 8240: 69-88 (2013)

42. Gmytrasiewicz, P.J., Lisetti, C. L.: Emotions and personality in agent design and modeling. J.-J.Ch. Meyer, M. Tambe (Eds.): Intelligent Agents VIII, LNAI 2333, SpringerVerlag Berlin Heidelberg, 21-31 (2002)

43. Ahn, H.S.: Designing of a Personality Based Emotional Decision Model for Generating Various Emotional Behavior of Social Robots. Advances in Human-Computer Interaction, Hindawi Publishing Corporation, Article ID 630808, 01-14 (2014)

44. Mohammad, Y., Nishida, T.: Modelling interaction dynamics during face-to-face interactions. Modeling Machine Emotions for Realizing Intelligence, Smart Innovation, Systems and Technologies, 1: 53-87 (2010)

45. Peters, E.: The functions of affect in the construction of preferences. In S. Lichtenstein and P. Slovic (Eds.), The construction of preferences. New York: Cambridge University Press (2006) 